\title{
Effect of Positive End Expiratory Pressure on Central Venous Pressure in Mechanically Ventilated Patients
}

\author{
Khaled Mohammed Al-Sayaghi ${ }^{1,2, *}$, Hassnaa Eid Shaban Mosa ${ }^{3}$, Masouda Hassan Atrous ${ }^{4}$, \\ Azza Hamdi El-Soussi ${ }^{5}$, Ahmed Youssef Ali $^{6}$, Sahar Hossni El-shenawi ${ }^{7}$ \\ ${ }^{1}$ Critical Care and Emergency Nursing, College of Nursing, Taibah University, KSA \\ ${ }^{2}$ Critical Care and Emergency Nursing, Faculty of Medicine and Health Sciences, Sana'a University, Yemen \\ ${ }^{3}$ Medical Surgical Nursing, Faculty of Nursing, Menoufia University, Egypt \\ ${ }^{4}$ Critical Care and Emergency Nursing, Faculty of Nursing, Jouf University, KSA \\ ${ }^{5}$ Critical Care and Emergency Nursing, Critical Care and Emergency Nursing Department, \\ Faculty of Nursing, Alexandria University, Egypt \\ ${ }^{6}$ Anesthesia and Surgical Intensive Care, Faculty of Medicine, Alexandria University, Egypt \\ ${ }^{7}$ Critical Care and Emergency Nursing, Critical Care and Emergency Nursing Department, \\ Faculty of Nursing, Alexandria University, Egypt \\ *Corresponding author: kalsayaghi@yahoo.com
}

Received January 17, 2019; Revised March 07, 2019; Accepted April 24, 2019

\begin{abstract}
Background: Central venous pressure (CVP) monitoring remains in common use as an index of circulatory filling and cardiac preload. Positive end-expiratory pressure (PEEP) in mechanically ventilated patients can affect CVP via increasing intra-thoracic pressure. Critical care nurses should be able to measure the CVP competently and identify the factors affecting its readings. Aim: The current study was conducted to determine the effect of PEEP on the CVP readings in mechanically ventilated patients. Methods: a descriptive design used in this study. A convenient sample of 200 adult critically ill patients of both sex, hemodynamically and respiratory stable, having a central venous catheter (CVC) in place, and attached to a mechanical ventilator and pulse oximeter were included in the study. The patient's baseline CVP was recorded while the patient connected to the mechanical ventilator, then the patients were temporary disconnected from the mechanical ventilator and the CVP measured again without the effect of PEEP. Results: About $40 \%$ of the study sample aged 45 to 64 years, $52.5 \%$ were males, $50 \%$ suffered from respiratory disorders, and $49 \%$ were overhydrated. Eighty eight percent of the study sample was on PEEP levels between 5 to $<10 \mathrm{cmH}_{2} \mathrm{O}$. The CVP readings while the patients connected to MV were higher than CVP reading while the patients without PEEP, but these differences were not significant. Conclusion: CVP readings are not significant affected by the PEEP up to $15 \mathrm{cmH}_{2} \mathrm{O}$. The CVP can be reliably measured while patients are connected to MV. Recommendations: Measurement of CVP can be obtained while the patient is connected to MV.
\end{abstract}

Keywords: PEEP, mechanical ventilation, central venous pressure, critically ill patients

Cite This Article: Khaled Mohammed Al-Sayaghi, Hassnaa Eid Shaban Mosa, Masouda Hassan Atrous, Azza Hamdi El-Soussi, Ahmed Youssef Ali, and Sahar Hossni El-shenawi, "Effect of Positive End Expiratory Pressure on Central Venous Pressure Readings in Mechanically Ventilated Patients." American Journal of Nursing Research, vol. 7, no. 3 (2019): 387-391. doi: 10.12691/ajnr-7-3-20.

\section{Introduction}

Hemodynamic monitoring plays an important and central role in the management of critically ill patients $[1,2,3]$. Hemodynamic monitoring aims to guide medical management, to prevent and/or treat organ failure, and to improve the outcomes of patients. Hemodynamic monitoring itself includes several different techniques [4]. In spite of the availability of several newer monitoring techniques, central venous pressure (CVP) monitoring remains in common use as an index of circulatory filling and cardiac preload [3]. CVP measurement is the most widely and frequently used variable in the intensive care unit (ICU). It provides important information about the cardio circulatory status, guide fluid resuscitation in critically ill patients, and should not be abandoned $[5,6]$. CVP is an indicator of right ventricular and, to a lesser extent, left ventricular preload and it also reflects the venous return and informs about right ventricular function [7].

CVP may be affected by intra-thoracic, pericardial, and intra-abdominal pressures [8]. Positive end-expiratory pressure (PEEP) in mechanically ventilated patients can affect CVP via increasing intra-thoracic pressure. Various reports exist on the direct relationship between the 2 pressures [7]. PEEP is the pressure above atmospheric pressure maintained throughout the respiratory cycle to prevent alveolar collapse at end-expiration [9]. The 
transmission of PEEP into the thoracic cavity depends on the properties of the lungs and the chest wall. When chest wall elastance is high, PEEP can significantly increase pleural pressure [10]. Shubin et al [11] suggested temporary disconnecting the patient from mechanical ventilator for valid CVP readings. However, disconnection the patient from MV may result in hypoventilation, hypoxia, bradycardia and hypotension [12]. A number of studies have now been conducted to determine if PEEP produces clinical changes in hemodynamic pressures or not. The researchers concentrate their attention on the effect of PEEP on the pulmonary artery pressure which is limited in use in our country.

\section{Aim of the Study}

The current study was conducted to determine the effect of positive end expiratory pressure on the central venous pressure in mechanically ventilated patients.

\section{Research Question}

Does the positive end expiratory pressure affect the central venous pressure readings in mechanically ventilated patients?

\section{Methods}

\subsection{Design and Settings}

A descriptive correlational research design was used to conduct the study in the ICUs of Alexandria Main University Hospital namely; the Casualty Intensive Care Unit (Unit I) and the General Intensive Care Unit (Unit III).

\subsection{Study Sample}

A convenient sample of 200 critically ill males and females patients with intrapulmonary and extrapulmonary disorders were enrolled in study. Patients were eligible for inclusion in the study if they were $\geq 18$ years old, having a central venous catheter (CVC) in place; attached to a mechanical ventilator and pulse oximeter; and hemodynamically and respiratory stable (heart rate of 50-130 beats/minute, mean arterial pressure (MAP) > $55 \mathrm{mmHg}$, respiratory rate of $8-30$ breaths/minute). Hemodynamically unstable patients (i.e. patients who have changes in systolic, mean, or diastolic blood pressure of $\geq 20 \mathrm{~mm} \mathrm{Hg}$; have changes in heart rate of $\geq 20$ beats/minute; have changes in CVP of $\geq 4 \mathrm{mmHg}$; have changes in infusion rate of cardiovascular drugs), patients on high levels PEEP $\left(>15 \mathrm{cmH}_{2} \mathrm{O}\right)$, and patients who have oxygen saturation $\left(\mathrm{SpO}_{2}\right)<93 \%$ were excluded from the study.

\subsection{Tools and Data Collection}

The researchers used a predesigned sheet to record the patient's characteristics (including the patient's age, sex, diagnosis, and hydration status), the PEEP level (from the mechanical ventilator settings), and the CVP levels while the patient connected to the mechanical ventilator and while the patient disconnected from the mechanical ventilator. The CVP was measured by a disposable water manometer which is the device applied for CVP monitoring in the settings of the study.

\subsubsection{Preparatory Phase (before obtaining the CVP readings)}

When the patient met the predetermined inclusion criteria and he/his family member agreed to take part in the study, the patency of the CVC and the efficiency of the bed (for rising and falling) were checked. When the patient needs any therapeutic interventions that could potentially affect the CVP readings such as tracheal suction or the nebulizer setting, it was done before CVP measurement and a 10-minutes stabilization period was allowed after suction. In addition, the nasogastric tube feeding must be given at least one hour before measuring the CVP to prevent aspiration that could be occurred in flat position.

The patient's characteristics and the PEEP level were recorded. Then the patient was placed in supine position in the middle of the bed in proper body alignment for 10 minutes stabilization period. The phlebostatic axis ( $4^{\text {th }}$ intercostals space at mid axillary line) was used as a reference point on the body and it was marked with ink on the side of the patient's chest to ensure accurate measurements $[13,14,15]$. The manometer zero point was leveled at the patient's phlebostatic axis and then the manometer was connected to the distal lumen of the CVC, after removing any air bubbles in the manometer.

\subsubsection{Implementation Phase (obtaining the CVP readings)}

The CVP was measured at the end of expiration while the patient was connected to mechanical ventilator using a water manometer with the zero point leveled at the phlebostatic axis. After that the patient was disconnected from mechanical ventilator and the CVP was measured at the end of expiration. Finally the patient was reconnected to mechanical ventilator immediately after measuring the CVP. During the CVP measurement, the blood pressure, heart rate, and $\mathrm{SpO}_{2}$ were monitored for any changes; if unacceptable changes occurred, the CVP measurement stopped, the patients reconnected to mechanical ventilator and excluded from the study.

The above steps were repeated three times (every two hours for 6 consecutive hours) and the mean of the three CVP readings was calculated and recorded. Any therapeutic interventions that could potentially raise or lower the CVP reading (such as suctioning, turning and volume replacement) were not carried out during measurement of the CVP or 10 minutes before [16]. The ventilator setting remained consistent throughout the 6 hours period of data collection. However, patients were excluded from the study in case of changing the ventilatory settings and also if the patient become hemodynamically unstable and need therapeutic interventions.

A pilot study was conducted on 10 critically ill mechanically ventilated patients to test the feasibility and 
applicability of the tools and methodology. The data was collected over period of thirteen months.

\subsection{Ethical Considerations}

Ethical approval was obtained from the research ethical committee at the faculty of nursing, Alexandria University. Approval to conduct the study was obtained from the responsible authority after explanation of the aim of the study. Informed consent was obtained from conscious patients or from the family members for unconscious patients before conducting the study. The patients and family members received an explanation of the research and it's objectives before obtaining their consent. Patient and their family members were assured that their consents are voluntary and they can withdraw from the study at any time without any harmful consequences. Patient and family members who agreed to participate in the study were provided with more verbal information about the study and they signed a consent form.

\subsection{Statistical Analysis}

Statistical analysis was done using the software Statistical Package for Social Sciences (SPSS) version 10. Data were expressed as frequencies, percentages, means, and standard deviations. For each patient the mean of the three CVP readings while the patient was connected to mechanical ventilator and the mean of the three CVP readings while the patient disconnected from mechanical ventilator were calculated and used for comparison. F-test (ANOVA) was used for analysis of variance and comparison between the means of more than two group means. $P$ value of 0.05 was used to assess the significance of the result.

\section{Results}

The results in Table 1 reveals that more than one third of the studied sample (39.5\%) aged 45 to less than 65 years, $26.5 \%$ aged 25 to less than 45 years, and $24.5 \%$ aged 65 years and more, while only $10 \%$ were below 25 years. More than half of the sample (52.5\%) was males. One half of the studied sample suffered from respiratory disorders while the other half suffered from extrapulmonary disorders: $32 \%$ cardiovascular disorders, $9.5 \%$ central nervous system disorders, $6.5 \%$ renal disorders, while only $2 \%$ suffered from other disorders (gastrointestinal and metabolic disorders). About half of the studied sample (49\%) were overhydrated (i.e. had signs and symptoms of fluid overload, positive fluid balance, normal or low sodium level, decreased hematocrit value, and normal or low blood urea), 38.5\% were adequately hydrated (had no signs and symptoms of fluid overload or deficit), while only $12.5 \%$ were dehydrated (had signs and symptoms of fluid volume deficit, negative fluid balance, increased or normal sodium level, and increased or normal blood urea). The majority of the studied sample $(88 \%)$ was on PEEP 5 to $<10 \mathrm{cmH}_{2} \mathrm{O}$, and $6 \%$ were on PEEP $<5 \mathrm{cmH}_{2} \mathrm{O}$, and
$6 \%$ were on PEEP10 $\mathrm{cmH}_{2} \mathrm{O}$ or more.

Table 1. Characteristics of the studied sample

\begin{tabular}{|c|c|c|}
\hline Characteristics & Number $(\mathbf{n}=\mathbf{2 0 0})$ & $\%$ \\
\hline \multicolumn{3}{|l|}{ Age in years } \\
\hline$\bullet<25$ & 20 & 10.0 \\
\hline$\cdot 25-<45$ & 53 & 26.5 \\
\hline - $45-<65$ & 79 & 39.5 \\
\hline$\bullet \geq 65$ & 48 & 24.0 \\
\hline \multicolumn{3}{|l|}{ Gender } \\
\hline - Male & 105 & 52.5 \\
\hline - Female & 95 & 47.5 \\
\hline \multicolumn{3}{|l|}{ Body systems alteration } \\
\hline - Intrapulmonary (respiratory). & 100 & 50.0 \\
\hline \multicolumn{3}{|l|}{ - Extrapulmonary: } \\
\hline - Cardiovascular & 64 & 32.0 \\
\hline - CNS & 19 & 9.5 \\
\hline - Renal & 13 & 6.5 \\
\hline - Others & 4 & 2.0 \\
\hline \multicolumn{3}{|l|}{ Hydration status } \\
\hline - Overhydrated & 98 & 49.0 \\
\hline - Adequately hydrated & 77 & 38.5 \\
\hline - Dehydrated & 25 & 12.5 \\
\hline \multicolumn{3}{|l|}{ PEEP $\left(\mathrm{cmH}_{2} \mathrm{O}\right)$} \\
\hline$\bullet 0-<5$ & 12 & 6.0 \\
\hline - $5-<10$ & 176 & 88.0 \\
\hline • $10-15$ & 12 & 6.0 \\
\hline
\end{tabular}

Table 2 shows the effect of PEEP and body systems alterations on the CVP readings. The CVP readings increased as the PEEP level increased, but the difference between the mean CVP readings while the patients on different PEEP levels was not significant. Similarly there was no significant difference between the mean CVP readings of the same patients when they were disconnected from MV (i.e. without PEEP). The mean CVP readings while the patients connected to $M V$ was higher than the mean CVP readings while the patients without PEEP, but this difference was not significant.

When patient on PEEP, the mean CVP reading of patients having CNS disorders was significantly lower than the mean CVP reading of the patients having pulmonary, cardiovascular, renal, and other systems disorders (10.85 VS 17.0, 18.66, and 18.83, respectively, $\mathrm{P}=<0.001)$. Same significant difference existed while the patients without PEEP. When comparing the mean differences between mean CVP while patients on PEEP and the mean CVP while the patients without PEEP, the mean difference of patients with other body systems disorders was significantly higher than the mean difference of patients with pulmonary, cardiovascular, $\mathrm{CNS}$, and renal disorders $(-5.00 \mathrm{VS}-1.50,-1.48,-2.53$, and -2.41 , respectively, $\mathrm{P}=0.001)$. 
Table 2. Effect of PEEP and body systems alterations on the CVP readings

\begin{tabular}{|c|c|c|c|}
\hline & $\begin{array}{l}\text { Mean CVP when patient on } \\
\text { PEEP }(\text { mean } \pm \text { SD })\end{array}$ & $\begin{array}{c}\text { Mean CVP when patient } \\
\text { without PEEP }(\text { mean } \pm \text { SD })\end{array}$ & Mean Difference \\
\hline \multicolumn{4}{|l|}{ PEEP $\left(\mathrm{cm} \mathrm{H}_{2} \mathrm{O}\right)$} \\
\hline$\bullet 0-<5$ & $16.82 \pm 6.33$ & $15.06 \pm 6.00$ & -1.75 \\
\hline$\cdot 5-<10$ & $17.14 \pm 7.77$ & $15.31 \pm 8.71$ & -1.83 \\
\hline$\cdot 10-15$ & $19.03 \pm 2.03$ & $18.08 \pm 2.69$ & -0.94 \\
\hline $\mathbf{F}$ & 0.704 & 1.063 & 1.293 \\
\hline $\mathbf{P}$ & 0.496 & 0.347 & 0.277 \\
\hline \multicolumn{4}{|l|}{ Systems alterations } \\
\hline - Intrapulmonary (respiratory) & $17.0 \pm 6.080^{\mathrm{a}}$ & $15.50 \pm 6.84^{\mathrm{a}}$ & $-1.50^{\mathrm{a}}$ \\
\hline - Cardiovascular & $18.66 \pm 5.90^{\mathrm{b}}$ & $17.18 \pm 6.39^{b}$ & $-1.48^{\mathbf{b}}$ \\
\hline$\cdot \mathrm{CNS}$ & $10.85 \pm 3.67^{\mathrm{c}}$ & $8.32 \pm 4.23^{\mathrm{c}}$ & $-2.53^{\mathrm{c}}$ \\
\hline - Renal & $18.83 \pm 5.96^{\mathrm{d}}$ & $16.42 \pm 6.42^{\mathrm{d}}$ & $-2.41^{\mathrm{d}}$ \\
\hline - Others & $8.17 \pm 0.00^{\mathrm{e}}$ & $3.17 \pm 0.00^{\mathrm{e}}$ & $-5.00^{\mathrm{e}}$ \\
\hline $\mathbf{F}$ & 6.364 & 7.101 & 4.116 \\
\hline $\mathbf{P}$ & $<0.001 *(\mathrm{c} \# \mathrm{a}, \mathrm{b}, \mathrm{d})^{\dagger}$ & $<0.001 *(\mathrm{c} \# \mathrm{a}, \mathrm{b}, \mathrm{d})^{\dagger}$ & $0.001 *(\mathrm{e} \# \mathrm{a}, \mathrm{b}, \mathrm{c}, \mathrm{d})^{\ddagger}$ \\
\hline Extrapulmonary & $16.94 \pm 6.45^{\mathrm{a}}$ & $15.02 \pm 7.07^{\mathrm{a}}$ & $-1.91^{\mathrm{a}}$ \\
\hline \multicolumn{4}{|l|}{ Intrapulmonary } \\
\hline - Obstructive & $20.49 \pm 8.20^{\mathrm{b}}$ & $19.64 \pm 9.07^{\mathbf{b}}$ & $-0.85^{b}$ \\
\hline - Restrictive & $15.88 \pm 4.70^{\mathrm{c}}$ & $14.53 \pm 4.99^{\mathrm{c}}$ & $-1.35^{\mathbf{c}}$ \\
\hline - Vascular & $17.89 \pm 4.52^{\mathrm{d}}$ & $17.44 \pm 4.86^{\mathrm{d}}$ & $-0.45^{\mathrm{d}}$ \\
\hline - Others & $15.19 \pm 4.52^{\mathrm{e}}$ & $12.61 \pm 5.27^{\mathrm{e}}$ & $-2.58^{\mathrm{e}}$ \\
\hline $\mathbf{F}$ & 3.087 & 4.146 & 5.588 \\
\hline $\mathbf{P}$ & $0.017^{*}(\mathrm{e} \# \mathrm{~b}, \mathrm{c}, \mathrm{d})^{\vee}$ & $0.003 *(\mathrm{a} \# \mathrm{~b}, \mathrm{~d})^{\vee v}$ & $<0.001 *(\mathrm{~b} \# \mathrm{e})^{\mathrm{vvv}}$ \\
\hline
\end{tabular}

*p-value indicates significant difference between the subgroups; ${ }^{\dagger}$ Significance difference existed between c and a,b,d; ${ }^{\ddagger}$ Significance difference existed between e and a,b,c,d. "Significance difference existed between e and b,c,d; ${ }^{\text {" }}$ Significance difference existed between a and b,d; and ${ }^{{ }^{* \bullet}}$ Significance difference existed between $\mathbf{b}$ and $\mathbf{e}$.

When the patients on PEEP, the mean CVP of patients having other pulmonary disorders was significantly lower than the mean CVP of patients having obstructive, restrictive, or vascular pulmonary disorders (15.19 VS $20.49,15.88$, and 17.89 , respectively, $P=0.017$ ). While the patients without PEEP, the mean CVP of patients having extrapulmonary disorders was significantly lower than the mean CVP of patients having obstructive and vascular pulmonary disorders (15.02 VS 19.64, and 17.44, respectively, $P=0.003$ ). When comparing the mean differences between mean CVP while patient on PEEP and the mean CVP while the patients without PEEP, there mean difference of patients with other pulmonary disorders was significantly higher than the mean difference of patients with obstructive pulmonary disorders $(-2.58$ VS $-0.85, P=<0.001$ ).

\section{Discussion}

Critically ill patients with the need for mechanical ventilation (MV) show complex interactions between respiratory and cardiovascular physiology. These interactions are important as they may guide the clinician's therapeutic decisions and, possibly, affect patient outcome [17]. Positive end-expiratory pressure (PEEP) ventilation is used to prevent alveolar collapse and improve oxygenation [18]. However, increased intrathoracic pressure from PEEP decreases venous return and lowers cardiac preload. Mechanically, the PEEP-mediated increase in intrathoracic pressure is transmitted to the right atrium, increasing right atrial pressure (RAP) $[19,20]$. The predicted or estimated RAP is known to be equal to the central venous pressure (CVP) [8]. Therefore, CVP consequently will be increased with increased RAP.

Findings of the current study revealed that high PEEP levels produce high CVP readings. The mean CVP readings while the patients on PEEP (i.e. connected to MV) were higher than the mean CVP readings while the patients without PEEP (i.e. disconnected from MV). However, these differences were not statistically significant. This finding inconsistent with Shojaee et al (2017) [7] finding that the application of PEEP was associated with statistically significant increase in CVP. Our finding could be attributed to low (physiological level) and moderate level of PEEP used in the majority of the current study sample. Another possible reason for this finding is the hypervolemic status of the majority of the sample which can alter the hemodynamic effect of PEEP on the CVP. 
Patients in ICU have instability in at least one of the vital body systems (cardiovascular, neurological, or respiratory systems) or at risk for this to develop. If these vital systems are not functioning appropriately, death can occur. The current study findings show that body system disorders that could affect the intravascular volume and the preload (renal and cardiovascular disorders) affect the CVP readings while the patient on PEEP or without PEEP. The effect of renal and cardiovascular impairment on the CVP readings could be due to its pathophysiological effects and impaired pumping action of the heart and its consequences, sodium and water retention, in addition to the effect of positive pressure ventilation (PPV).

\section{Conclusions}

Central venous pressure readings are not significantly affected by the PEEP up to $15 \mathrm{~cm} \mathrm{H}_{2} \mathrm{O}$. The CVP can be reliably measured while patients are connected to $\mathrm{MV}$. Body systems alteration is among the factors affecting the CVP readings.

\section{Recommendations}

The critical care nurse does not need to disconnect the patient from MV for accurate CVP measurement as the change in the mean CVP in relation to different level of PEEP is small and a wide variation in CVP readings was not found.

\section{References}

[1] Vincent J, Rhodes A, Perel A, Martin G, Rocca G, Vallet B, et al. Clinical review: update on hemodynamic monitoring - a consensus of 16. Critical Care 2011; 15(4): 229.

[2] Saugel B, Malbrain M, Perel A. Hemodynamic monitoring in the era of evidence-based medicine. Critical Care 2016; 20: 401.

[3] Dan M, Varghese L. Correlation between Peripheral Venous Pressure and Central Venous Pressure Monitored by CVP Manometer: an Observational Study. International Journal of Scientific and Research Publications 2015; 5(8).
[4] Huygh J, Peeters Y, Bernards J, Malbrain M. Hemodynamic monitoring in the critically ill: an overview of current cardiac output monitoring methods. Research 2016; 5: 2855.

[5] Roger C, Muller L, Riou B, Molinari N, Louart B, Kerbrat H, Tebou J, Lefrant J. Comparison of different techniques of central venous pressure measurement in mechanically ventilated critically ill patients. British Journal of Anaesthesia 2017; 118(2): 223.

[6] De Backer D, Vincent J. Should we measure the central venouspressure to guide fluid management? Ten answers to 10 questions. Critical Care 2018; 22: 43.

[7] Shojaee M, Sabzghabaei A, Alimohammadi H, Derakhshanfar, Amini A, Esmailzadeh B. Effect of Positive End-Expiratory Pressure on Central Venous Pressure in Patients under Mechanical Ventilation. Emergency 2017; 5 (1): e1.

[8] Das R, Lee Y, Oh S. The Determinants Of Mean Central Venous Pressure For Shock Patients. J Clin Trial Cardiol. 2018; 5(2): 1-5.

[9] Alviar L, Miller P, McAreavey D, Katz J, Lee B, Moriyama B, et al. Positive Pressure Ventilation in the Cardiac Intensive Care Unit. J Am Coll Cardiol 2018; 72(13): 1532-53.

[10] Chen H, Xu M, Yang Y, Chen K, Xu J, Zhang Y, et al. Effects of increased positive end-expiratory pressure on intracranial pressure in acute respiratory distresssyndrome: a protocol of a prospective physiological study. BMJ 2016; 6(11): e012477.

[11] Shubin H, and Will M. Routine central venous catheterization for management of critically ill patients. IN: Ingelfinger F, Ebert R, Finland $\mathrm{M}$, and Rolman A, editor. Controversy in Internal Medicine. W.B. Sauanders Co, Piladelphia, 1974, 177-184.

[12] Kumar BU. Handbook of mechanical ventilation. $2^{\text {nd }}$ ed. Jaypee Brothers Medical Pub, New Delphi, 2016.

[13] Finkelmeier BA. Cardiothoracic surgical nursing. $2^{\text {nd }}$ ed. Lippincott, Philadelphia, 2000, 277-88.

[14] Kirchhoff K, Piano M, Patel M. Arterial pressure readings: variations with positions and transducer level. Nursing Research 1984; 33(6): 343-5.

[15] Pennington L, Smith C. Leveling when monitoring central blood pressure: an alternative method. Heart Lung 1980; 9(6): 1053-9.

[16] Calow L, Pieper B. Effect of back rest elevation on central venous pressure in pediatric cardiac surgery. Nursing Research 1998; 38(6): 336-8.

[17] Martin G, Olivier W, David B, Stefan B. Basic concepts of heartlung interactions during mechanical ventilation. Swiss Med Wkly. 2017; 147: w14491.

[18] Backhaus R, Torka E, Ertl M, Kirzinger L, Wagner A, Baldaranov $D$, et al. Influence of Positive End-Expiratory Pressure Ventilation on Cerebral Perfusion and Cardiac Hemodynamics. Journal of Depression and Anxiety 2017; (6): 4: 285.

[19] Kuhn B, Bradley A, Dempsey T, Puro A, Adams J. Management of mechanical ventilation in decompensated heart failure. J. Cardiovasc. Dev. Dis. 2016; 3 (4): 33.

[20] Sen O, Doventas Y. Effects of different levels of end-expiratory pressure on hemodynamic, respiratory mechanics and systemic stress response during laparoscopic cholecystectomy. Rev Bras Anestesiol. 2017; 67(1): 28-34. 